\title{
Evaluation of renal function in clinical practice: the basics
}

\author{
Alessia Casola, ${ }^{1}$ Maria del Mar Jordana Sanchez, ${ }^{1}$ Simona Detrenis, ${ }^{1}$ Laura Bianchi, ${ }^{2}$ Sarah Pioli, ${ }^{1,3}$ \\ Francesca Spagnoli, ${ }^{4}$ Michele Meschi ${ }^{1}$ \\ ${ }^{1}$ Internal Medicine Unit and Hypertension Center, Parma Local Health Authority, Borgo Val di Taro (PR); ${ }^{2}$ Pediatric Unit, \\ Parma University Hospital, Parma; ${ }^{3}$ Nephrology Unit, Parma Local Health Authority, Parma; ${ }^{4}$ Hospital Health Management, \\ Parma Local Health Authority, Borgo Val di Taro (PR), Italy
}

\begin{abstract}
The evaluation of renal function in Internal Medicine plays an important role in the staging and prognosis of chronic kidney disease, but also for the daily clinical activity (for example, dosage of drugs). This review describes the options for estimating renal function that are currently in use, underlining limits and indications.
\end{abstract}

\section{Introduction}

Chronic kidney disease (CKD) is currently defined as decreased kidney function and/or kidney damage which persists for at least 3 months. Renal impairment may be expressed by a reduction of glomerular filtration rate (GFR) below $60 \mathrm{~mL} / \mathrm{min}$ per $1.73 \mathrm{~m}^{2}$, whereas the so-called kidney damage most frequently appears with an increased urinary albumin excretion. On the basis of these findings, CKD has been categorized into 5 stages. Several analyses of prospective cohort studies have clarified the association of each level of estimated GFR and increased urinary albumin excretion with end-stage renal disease (ESRD) and total or cardiovascular mortality. On the basis of these data, the Italian

Correspondence: Michele Meschi, Internal Medicine Unit and Hypertension Center, Parma Local Health Authority, via Benefattori 12, 43043 Borgo Val di Taro (PR), Italy.

E-mail: mmeschi@ausl.pr.it

Key words: Serum creatinine; MDRD equation; CKD-EPI equation; proteinuria.

Contributions: the authors contributed equally.

Conflict of interest: the authors declare no potential conflict of interest.

Received for publication: 10 November 2018.

Revision received: 21 December 2018.

Accepted for publication: 2 January 2019.

This work is licensed under a Creative Commons Attribution NonCommercial 4.0 License (CC BY-NC 4.0).

(C) Copyright A. Casola et al., 2019

Licensee PAGEPress, Italy

Italian Journal of Medicine 2019; 13:32-37

doi:10.4081/itjm.2019.1112
Department of Health, the National Institute of Health and the Italian Society of Nephrology have updated the official guidelines in keeping with international consensus, subdividing the stage 3 into stages $3 \mathrm{a}$ (GFR $45-59 \mathrm{~mL} / \mathrm{min}$ per $1.73 \mathrm{~m}^{2}$ ) and $3 \mathrm{~b}$ (GFR 30-44 $\mathrm{mL} / \mathrm{min}$ per $1.73 \mathrm{~m}^{2}$ ). In addition, the suffix $p$ was introduced to indicate the presence of urinary loss of proteins in the staging of CKD, defined as urine albumin-creatinine ratio (UACR) ${ }^{1}$ (Tables 1 and 2).

Often in Internal Medicine the methods of evaluation of renal function are used interchangeably, but it would be important to know the basic differences between them, from a mnemonic point of view, for a correct use in clinical practice.

\section{Glomerular filtration rate}

\section{Clinical significance}

Under normal conditions the functional units of the kidney, the glomeruli, can filter around $180 \mathrm{~L}$ per day $(125 \mathrm{~mL} / \mathrm{min})$ of plasma. The normal value of GFR depends on age, sex and body size of the patient and is approximately between 120 and $130 \mathrm{~mL} / \mathrm{min}$ per $1.73 \mathrm{~m}^{2}$ in men and women, respectively, with significant changes even among normal individuals. ${ }^{2}$

In patients with CKD, a reduction in GFR may indicate the progression of the underlying disease or the development of further acute and often reversible injury, linked to a transient reduction of renal perfusion or the use of nephrotoxic drugs.

The value of GFR at steady state has prognostic implications and forms the basis of clinical staging for patients with CKD. There is no precise correlation between the loss of nephrons and the reduction of GFR, since the kidney adapts to the loss of functional units by hyperfiltration, and at the same time increases the reabsorption of solutes and water in the residual functioning nephrons. Consequently, a stable GFR 
does not necessarily imply a stable CKD. It is always necessary to look for signs of CKD progression that may accompany the variation in GFR, including changes in urinary sediment, urinary protein loss and alterations in blood pressure.

Indeed, an increase in GFR is not always synonymous with improvement of CKD and can mean the presence of hyperfiltration, caused by hemodynamic and non-hemodynamic factors, typical of some phases of major systemic diseases (e.g. diabetes mellitus). ${ }^{3}$

\section{Creatinine clearance}

Since the measurement of GFR by reference methods is complex, costly and not widely available, its routine evaluation is performed using endogenous biomarkers. A method is the determination of the urinary clearance of an ideal filtration biomarker (FBM), defined as a solute that is freely filtered, neither secreted nor reabsorbed, and not changed during its excretion by the kidney. The equation to calculate its clearance is:

$F B M C l=(U F R \cdot U F B M) \div S F B M$

where SFBM is the serum concentration of FBM, UFBM is its urinary concentration, and UFR is the urine flow rate. In this condition, the filtered load is equal to the rate of urinary excretion:
$G F R \cdot S F B M=U F R \cdot U F B M$

Consequently, by substitution into previous equation:

$$
F B M C l=G F R
$$

Endogenous FBMs can be used to evaluate GFR only in individuals with stable kidney function: in the course of acute kidney injury, the GFR is markedly reduced, but there has not yet been time for the FBM to accumulate and reflect the degree of kidney disease severity.

Between FBMs, creatinine is derived from the metabolism of creatine in skeletal muscle and is released into the circulation at a relatively constant rate. Serum creatinine ( $\mathrm{SCr}$ ) is freely filtered across the glomerulus and is neither reabsorbed nor metabolized by renal parenchyma. However, approximately $10-40$ percent of urinary creatinine is derived from secretion in the proximal tubule. At the steady state, creatinine excretion (GFR $\cdot \mathrm{SCr}$ ) equals creatinine production, which is relatively constant on a stable diet. Thus, the $\mathrm{SCr}$ concentration varies inversely with the GFR.

The mean $\mathrm{SCr}$ values for men and women were 1.12 and $0.94 \mathrm{mg} / \mathrm{dL}$, respectively. The mean values also varied by race. It is presumed that the higher values for blacks and lower values for Hispanics

Table 1. Chronic kidney disease stages.

\begin{tabular}{lll}
\hline Stage & eGFR & Clinical evidences \\
\hline 1 & $\leq 90 \mathrm{~mL} / \mathrm{min}$ per $1.73 \mathrm{~m}^{2}$ & Kidney damage \\
\hline 2 & $60-89 \mathrm{~mL} / \mathrm{min}$ per $1.73 \mathrm{~m}^{2}$ & Kidney damage \\
\hline $3 \mathrm{a}$ & $45-59 \mathrm{~mL} / \mathrm{min}$ per $1.73 \mathrm{~m}^{2}$ & Normal UACR, microalbuminuria or macroalbuminuria \\
\hline $3 \mathrm{~b}$ & $30-44 \mathrm{~mL} / \mathrm{min}$ per $1.73 \mathrm{~m}^{2}$ & Normal UACR, microalbuminuria or macroalbuminuria \\
\hline 4 & $15-29 \mathrm{~mL} / \mathrm{min}$ per $1.73 \mathrm{~m}^{2}$ & Normal UACR, microalbuminuria or macroalbuminuria \\
\hline 5 & $<15 \mathrm{~mL} / \mathrm{min}$ per $1.73 \mathrm{~m}^{2}$ & Normal UACR, microalbuminuria or macroalbuminuria \\
\hline
\end{tabular}

eGFR, estimated glomerular filtration rate; UACR, urine albumin-creatinine ratio.

Table 2. Albuminuria and proteinuria.

\section{4-h urine albumin}

(mg/24 h)
Spot urine albumin

albumin-creatinine ratio

(mg/g)

\begin{tabular}{ll}
\hline Albuminuria & $<20$ \\
Normal & $30-300$ \\
Microalbuminuria & $>300$ \\
Macroalbuminuria & \\
\hline Proteinuria & $<150 \mathrm{mg} / 24 \mathrm{~h}$ \\
Physiological & $150-300 \mathrm{mg} / 24 \mathrm{~h}$ (urinary dipstick undetectable) \\
Microproteinuria & $>300 \mathrm{mg} / 24 \mathrm{~h}$ (protein-creatinine ratio $>200 \mathrm{mg} / \mathrm{g}$ ) \\
Overt proteinuria &
\end{tabular}


reflect greater and lesser, respectively, muscle mass and creatinine excretion.

The shape of the curve relating the GFR to $\mathrm{SCr}$ has an important clinical implication. In patients with slightly altered baseline renal function values, a small rise in SCr usually reflects a marked fall in GFR, whereas a marked rise in $\mathrm{SCr}$ in patients with advanced disease reflects a small absolute reduction in GFR (Figure 1). In facts, a reduction in GFR results in increased tubular creatinine secretion that reduces the rise in SCr. Thus, a 50 percent reduction in GFR does not produce a doubling of $\mathrm{SCr}$, but rather a smaller rise than would have occurred if the decrease in GFR had occurred without an increase in secretion.

If the effect of secretion is ignored, then all the filtered creatinine (GFR - SCr) will be excreted (UFR - urine creatinine concentration [UCr]). The equations described above:

$G F R \cdot S F B M=U F R \cdot U F B M$

$F B M C l=G F R$

become

$G F R \cdot S C r=U F R \cdot U C r$

$C r C l=G F R=[U F R \cdot U C r] \div S C r$

Obviously, the $\mathrm{Cr} \mathrm{Cl}$ formula tends to exceed the true GFR because of the fraction of urinary creatinine that is derived from its tubular secretion. This error has been balanced by an equal opposing in the detection of the SCr using the alkaline picrate method. Today the standardization of $\mathrm{SCr}$ assays should abolish this error in $\mathrm{SCr}$, and $\mathrm{Cr} \mathrm{Cl}$ will be consistently 10 to 20 percent higher than GFR.

The $\mathrm{Cr} \mathrm{Cl}$ is usually determined from a 24-h urine collection. In a $70 \mathrm{~kg}$ man with $\mathrm{SCr}=1.4 \mathrm{mg} / \mathrm{dL}$ and $\mathrm{UCr}=100 \mathrm{mg} / \mathrm{dL}$, UFR $1.5 \mathrm{~L} / 24 \mathrm{~h}$ is equal to 1500

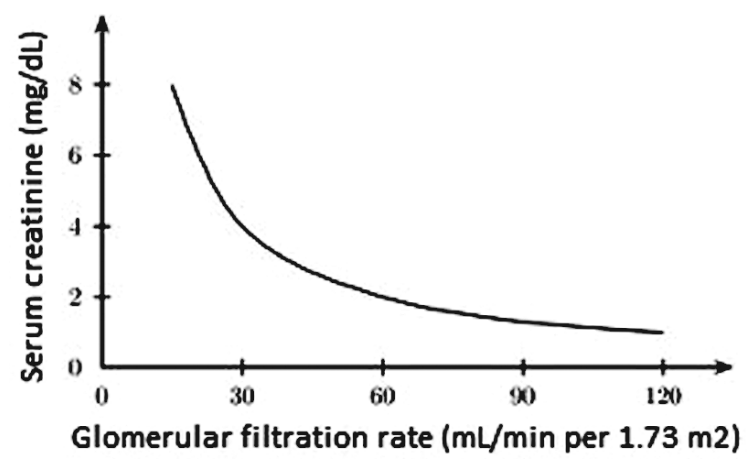

Figure 1. Relationship between serum creatinine and glomerular filtrate rate.
$\mathrm{mL} / 24 \mathrm{~h}$. Divided by 1440 (the number of minutes in a day), UFR becomes $1.04 \mathrm{~mL} / \mathrm{min}$. Consequently,

$\mathrm{CrCl}=[1.04 \cdot 100] \div 1.4=74.28 \mathrm{~mL} / \mathrm{min}$

It is important to remember that there are several key limitations of routinely using SCr to estimate GFR. Subjects with significant variations in dietary intake or reduction in muscle mass produce different amounts of creatinine. Moreover, $\mathrm{SCr}$ rises with rhabdomyolysis (up to $2.5 \mathrm{mg} / \mathrm{dL}$ per day), in which its abnormal release from injured muscle could be an explanation. Finally, extrarenal creatinine elimination is increased in advanced CKD (GFR $<15 \mathrm{~mL} / \mathrm{min}$ per $\left.1.73 \mathrm{~m}^{2}\right)$ and $\mathrm{SCr}$ concentration is lower than would be expected from the GFR in this setting, probably because of increased intestinal bacterial creatininase activity. ${ }^{4}$

\section{Cockcroft-Gault equation}

Among the equations that allow estimating GFR at steady state, but not in the conditions of acute deterioration of renal function, the Cockcroft-Gault equation considers some clinical variables that should compensate for changes in production and secretion of creatinine:

$\mathrm{CrCl}(\mathrm{mL} / \mathrm{min})=[(140-$ age $) \cdot \mathrm{kg}$ body weight $] \div$

$(\mathrm{SCr} \cdot 72)(\cdot 0.85$ in women)

As mentioned, the production of creatinine decreases with age and increases with body weight. Since the formula is not regulated for the body surface area and has been studied before the standardization of the $\mathrm{SCr}$ assay, it can result in an overestimation of the $\mathrm{Cr} \mathrm{Cl}$ of about $10-40 \%$.

\section{Modification of diet in renal disease study equation}

From the data on patients enrolled in modification of diet in renal disease (MDRD) study (predominantly Caucasian non-diabetic patients, mean age 51 years \pm 12.7 years), who had a GFR calculated through the urinary clearance of the iothalamate marker, the MDRD equation is derived, which uses standardized measurement of SCr:

eGFR $\left(\mathrm{mL} / \mathrm{min}\right.$ per $\left.1.73 \mathrm{~m}^{2}\right)=175 \cdot \mathrm{SCr}^{-1.154}$. age $e^{-0.203} \cdot 0.742$ (in women) $\cdot 1.21$ (in blacks)

The equation presents a lack of accuracy in obese patients and in those with GFR around normal. ${ }^{5}$

\section{Chronic Kidney Disease EPIdemiology collaboration study equation}

In order to provide a more accurate GFR evaluation among individuals with normal or slightly 
reduced GFR (i.e. greater than $60 \mathrm{~mL} / \mathrm{min}$ for 1.73 $\mathrm{m}^{2}$ ), various clinical data, collected and validated through nearly 20 studies in patients with and without CKD, led to the definition of the CKD-EPI (Chronic Kidney Disease EPIdemiology collaboration) equation. A meta-analysis including over 1,000,000 adult patients, observed for approximately 7 years to assess overall and cardiovascular mortality and ESRD, shows that the use of the CKD-EPI equation causes a lower estimation of the prevalence of CKD and a more accurate risk prediction for adverse outcomes than the MDRD study equation. The CKD-EPI equation shows better performances for higher levels of GFR and in subgroups defined by sex, race, diabetes and renal transplantation, in the elderlies and at higher levels of body mass index (BMI). In contrast, the MDRD study equation has better performance at lower levels of GFR. At lower BMI levels $\left(<20 \mathrm{~kg} / \mathrm{m}^{2}\right)$, there is a greater overestimation of the GFR measured with the CKD-EPI equation than the MDRD study equation, but the small size of this sample would require further investigations. ${ }^{6}$

\section{Serum cystatin C}

Other endogenous FBMs have been evaluated to provide a more accurate estimate of GFR, including cystatin $\mathrm{C}$, which is a low molecular weight protein produced at a relatively constant rate, filtered by the glomerulus, not reabsorbed and metabolized in the renal tubules. Serum levels may increase in elderly male patients, with a larger body surface area, in the course of inflammation or chronic illness (e.g. diabetes mellitus and dysthyroidism). Despite these biases, the combination of $\mathrm{SCr}$ and cystatin $\mathrm{C}$ in a single equation could provide a more accurate estimate of GFR than equations using creatinine or cystatin $\mathrm{C}$ alone. ${ }^{7}$ After smearing adjustment $\left(\mathrm{R}^{2}=0.92\right.$, standard deviation of residual $=0.096$, $\mathrm{P}<0.001$ for model fitting):

eGFR $\left(\mathrm{mL} / \mathrm{min}\right.$ per $\left.1.73 \mathrm{~m}^{2}\right) \approx 169 \cdot \mathrm{SCr}^{-0.608}$.

ScysC $C^{-0.63} \cdot$ age $^{-0.157} \cdot 0.83$ (in women)

\section{Diagnostic problems in advancing age}

It is recognized that eGFR, as estimated by creatinine clearance, can decrease with age. This decrease in creatinine clearance may not be appreciated by measurement of $\mathrm{SCr}$ in elderly patients. As we have seen, there is a nonlinear inverse relationship between eGFR and the $\mathrm{SCr}$, which reflects muscular mass, age, and sex of the subject under examination, as it is a muscular creatine catabolite. In fact, aged subjects generally experience a decrease in muscle mass, which, in turn, is associated with a decrease in muscle creatinine production. Because the decrease in creatinine production may parallel the physiologic decrease in eGFR, SCr may remain unchanged despite declining renal function. Thus, elderly patients with the reduced total muscular mass typical of old age, often have a truly significant decrease in GFR even when their $\mathrm{SCr}$ values appear normal. In addition to variations in the estimation of renal function, the eGFR really decreases gradually with aging over time. Renal function is said to decline after the age of 40 years at rates of up to $1 \mathrm{~mL} / \mathrm{min} /$ year of eGFR, associated with a greater fall in total renal blood and plasma flow, at an approximate rate of $10 \%$ per decade. Actually, among the various hypotheses for kidney aging, alteration in glomerular hemodynamics and imbalance between synthesis and degradation of matrix proteins causing glomerulosclerosis are favored. The aging human kidney develops progressive glomerulosclerosis and interstitial fibrosis, and the number of nephron units becomes significantly decreased per unit tissue mass. Both renal weight and size decrease steadily with increasing age. Microscopically, the number of renal glomeruli decreases in parallel with the total renal mass, particularly in the cortex. Glomerular alterations appear with thickening of the glomerular basement membrane and hyaline degeneration of the glomerulus. Glomerular basement membrane thickening may result in a loss of lobulation of the glomerular tuft and in a decreased effective filtering surface. Furthermore, there is a progressive increase in the number of mesangial cells, accompanied by an overall expansion of mesangial tissue, with an increase from $8 \%-10 \%$ of total glomerular volume at 40 years of age to $10 \%-15 \%$ by 80 years of age. ${ }^{8}$

\section{Urinary protein excretion}

In normal subjects, low molecular weight proteins and small amounts of albumin are filtered from the renal glomerulus. The overall urinary protein excretion (UPE) is less than $150 \mathrm{mg} / 24 \mathrm{~h}$. Larger values, confirmed in subsequent measurements, are often an expression of an increase in glomerular permeability and abnormal filtration of macromolecules, such as albumin.

\section{Amounts of proteinuria}

The degree of UPE is prognostically important in patients with primary and secondary glomerular diseases; higher levels of proteinuria are associated with faster progression to renal failure. In the absence of GFR abnormalities, changes in urinary sediment or known systemic diseases, isolated proteinuria is usually asymptomatic and occurs in a non-nephrotic 
range, i.e. with quantities of less than $3.5 \mathrm{~g} / 24 \mathrm{~h} .{ }^{9}$

The specific evaluation of albuminuria can be an effective way of detecting early CKD. The normal rate of urinary albumin excretion (UAR) is less than 20 $\mathrm{mg} / 24 \mathrm{~h}(15 \mathrm{mcg} / \mathrm{min})$. A persistent UAR between 30$300 \mathrm{mg} / 24 \mathrm{~h} \quad(20-200 \mathrm{mcg} / \mathrm{min})$ is called microalbuminuria. In particular, in patients with diabetes, this is usually indicative of incipient nephropathy. Also, in non-diabetic subjects, the presence of microalbuminuria is associated with an increased cardiovascular risk. An UAR above 300 $\mathrm{mg} / 24 \mathrm{~h}(200 \mathrm{mcg} / \mathrm{min})$ is evaluated as severely increased albuminuria or macroalbuminuria, the level at which the standard dipstick becomes positive. At this level, much of the protein in the urine consists of albumin (overt proteinuria). ${ }^{10}$

The gold standard for measuring protein excretion is a 24-h urine collection, but due to the difficulties of this procedure some alternatives have been proposed. Among these, the urine protein-creatinine ratio (UPCR) or UACR in an early morning urine sample after avoiding exercise can be used to estimate proteinuria for $24 \mathrm{~h}$. Usually, the concentration of proteins in a spot sample of urine is measured in $\mathrm{mg} / \mathrm{dL}$ and is divided by the concentration of creatinine in the urine, also measured in $\mathrm{mg} / \mathrm{dL}$, then producing a number that estimates the protein excretion of $24 \mathrm{~h}$ in $\mathrm{g} / 24 \mathrm{~h}$. Since the average $24-\mathrm{h}$ excretion of creatinine in the urine for the population is about $1000 \mathrm{mg} / 24 \mathrm{~h}$ for $1.73 \mathrm{~m}^{2}$ and the denominator of the UPCR is expressed in grams of creatinine, UPCR is an accurate estimate of proteinuria at $24 \mathrm{~h}$ only in individuals who excrete $1000 \mathrm{mg} / 24 \mathrm{~h}$ of creatinine. In individuals with a large muscle mass, in which the excretion of creatinine can be much higher than $1000 \mathrm{mg} / 24 \mathrm{~h}$, UPCR will underestimate proteinuria. On the contrary, in a cachectic patient, in which the excretion of creatinine can be much lower than $1000 \mathrm{mg} / 24 \mathrm{~h}$, UPCR will overestimate proteinuria. ${ }^{11}$

\section{Clinical types of proteinuria}

Isolated proteinuria can also occur as transient proteinuria $(\mathrm{TrP})$ or orthostatic proteinuria $(\mathrm{OP})$. If $\mathrm{TrP}$ and OP are excluded, the patient has persistent isolated proteinuria (PIP). All these conditions generally involve a total UPE generally less than $1 \mathrm{~g} / 24 \mathrm{~h}$.

$\mathrm{TrP}$ is common, especially in young individuals, and may occur during protracted physical exercise, fever or urinary tract infections, and may be caused by changes in glomerular permeability mediated by substances such as angiotensin II or vasoactive amines. ${ }^{12}$

$\mathrm{OP}$, equally common in patients younger than 30 years, is characterized by an increase in UPE in the upright position but by normal UPE when the patient is supine. Also in this case, neurohumoral activation and altered glomerular hemodynamics can play a significant role.

In contrast, PIP usually reflects an underlying renal or systemic disorder. In particular, all patients with PIP above $500 \mathrm{mg} / 24 \mathrm{~h}$ for total proteins or greater than $300 \mathrm{mg} / 24 \mathrm{~h}$ for albumin should be referred to a nephrologist for decisions regarding further evaluation and management. ${ }^{13}$

When the constant presence of heavy proteinuria (UPE greater than $3.5 \mathrm{~g} / 24 \mathrm{~h}$ ) is not accompanied by the nephrotic syndrome (hypoalbuminemia, peripheral edema), it is however suggestive of a glomerulopathy. For example, this occurrence could be an expression of secondary focal segmental glomerulosclerosis due to diabetes. Heavy proteinuria with or without nephrotic syndrome may occur in association with a wide variety of diseases. In adults, about $30 \%$ of patients have a systemic disease such as diabetes mellitus, amyloidosis or systemic lupus erythematosus; the remaining cases are usually due to primary renal disorders such as minimal change disease, focal segmental glomerulosclerosis and membranous nephropathy. ${ }^{14}$

\section{Instrumental types of proteinuria}

Measurement of both albumin and total protein urine concentrations (with separate tests or with a urine protein electrophoresis) can help determine the type of proteinuria.

Glomerular proteinuria is due to the increase in the filtration of macromolecules, such as albumin, through the wall of the glomerular capillaries. This is a sensitive marker for the presence of glomerular disease. Proteinuria associated with diabetic nephropathy and other glomerular diseases, as well as more benign causes, such as orthostatic or exerciseinduced proteinuria, fall into this category. ${ }^{15}$

Low molecular weight proteins (beta2microglobulin, retinol-binding protein, light chains of immunoglobulins) are normally filtered by the glomerulus. All conditions that alter the reabsorption in the proximal tubule cause the appearance of the socalled tubular proteinuria (TP). Often TP is not clinically diagnosed, because the protein dipstick is not highly sensitive for detecting proteins other than albumin and because the amount of non-albumin excreted protein is low.

In some hematological neoplasms, such as in monoclonal gammopathies, the abnormal production of light chains of the immunoglobulins that are filtered exceeds their capacity for proximal reabsorption, giving rise to a particular form of proteinuria, defined as overflow proteinuria.

Finally, in the course of urinary tract infections abnormal increases of UPE give rise to the so-called post-renal proteinuria, often accompanied by leukocyturia. ${ }^{16}$ 


\section{References}

1. Meschi M, Degli Esposti E, Degli Esposti L, et al. Referral to sub-specialists: who have the most to gain from early specialist intervention among patients with markers of renal disease? Ital J Med 2014;8:161-8.

2. Chakkera HA, Denic A, Kremers WK, et al. Comparison of high glomerular filtration rate thresholds for identifying hyperfiltration. Nephrol Dial Transplant 2018 [Epub ahead of print].

3. Vidal-Petiot E, Flamant M. Measurement and estimation of glomerular filtration rate. Nephrol Ther 2017;13:560-8.

4. Crass RL, Pai MP. Estimating renal function in drug development: time to take the fork in the road. J Clin Pharmacol 2018 [Epub ahead of print].

5. Schwandt A, Denkinger $M$, Fasching $P$, et al. Comparison of MDRD, CKD-EPI, and Cockcroft-Gault equation in relation to measured glomerular filtration rate among a large cohort with diabetes. J Diabet Complicat 2017;31:1376-83.

6. Chukwuonye II, Ogah OS, Anyabolu EN, et al. Prevalence of chronic kidney disease in Nigeria: systematic review of population-based studies. Int J Nephrol Renovasc Dis 2018;11:165-72.

7. Zhou B, Zou H, Xu G. Clinical utility of serum cystatin $\mathrm{C}$ in predicting diabetic nephropathy among patients with diabetes mellitus: a meta-analysis. Kidney Blood Press Res 2016;41:919-28.

8. Detrenis S, Meschi M, Bertolini L, Savazzi G. Contrast medium administration in the elderly patient: is advancing age an independent risk factor for contrast nephropathy after angiographic procedures? J Vasc Interv Radiol 2007; 18:177-85.

9. Kattah A, Milic N, White W, Garovic V. Spot urine protein measurements in normotensive pregnancies, pregnancies with isolated proteinuria and preeclampsia. Am J Physiol Regul Integr Comp Physiol 2017;313: R418-24.

10. Chatzikyrkou C, Menne J, Izzo J, et al. Predictors for the development of microalbuminuria and interaction with renal function. J Hypertens 2017;35:2501-9.

11. Bartz SK, Caldas MC, Tomsa A, et al. Urine albuminto-creatinine ratio: a marker of early endothelial dysfunction in youth. J Clin Endocrinol Metab 2015; 100:3393-9.

12. Shephard RJ. Exercise proteinuria and hematuria: current knowledge and future directions. J Sports Med Phys Fitness 2016;56:1060-76.

13. Feng CY, Xia YH, Wang WJ, et al. Persistent asymptomatic isolated hematuria in children: clinical and histopathological features and prognosis. World J Pediatr 2013;9:163-8.

14. Liebeskind DS. Nephrotic syndrome. Handb Clin Neurol 2014;119:405-15.

15. Snyder S, John JS. Workup for proteinuria. Prim Care 2014;41:719-35.

16. Rajkumar SV, Dimopoulos MA, Palumbo A, et al. International Myeloma Working Group updated criteria for the diagnosis of multiple myeloma. Lancet Oncol 2014;15:e538-48. 